\title{
Synthesis, Anticandidal Activity and Molecular Docking Study of Some New Imidazole Derivatives ${ }^{\dagger}$
}

\author{
Begüm Nurpelin Sağlık 1,2,*, Ayşen Işık 1, Ulviye Acar Çevik 1,2, Yusuf Özkay 1,2 and \\ Serkan Levent 1,2 \\ 1 Department of Pharmaceutical Chemistry, Faculty of Pharmacy, Anadolu University, 26470 Eskişehir, \\ Turkey; aysenpekbag@gmail.com (A.I.); uacar@anadolu.edu.tr (U.A.C.); yozkay@anadolu.edu.tr (Y.Ö.); \\ serkanlevent@anadolu.edu.tr (S.L.) \\ 2 Doping and Narcotic Compounds Analysis Laboratory, Faculty of Pharmacy, Anadolu University, \\ 26470 Eskişehir, Turkey \\ * Correspondence: bnsaglik@anadolu.edu.tr \\ + Presented at the 1st Molecules Medicinal Chemistry Symposium, Barcelona, Spain, 8 September 2017. \\ Published: 19 October 2017
}

The azole pharmacophore is still regarded as a viable lead structure for the synthesis of more effective antifungal agents [1-3]. In this study, new 2-substituted- $N$-[4-(1H-imidazole-1-yl) phenyl] acetamide $(\mathbf{5} \mathbf{a}-\mathbf{5 g}, \mathbf{6 a}-\mathbf{6 n})$ derivatives were synthesized and the antifungal activities of these compounds were evaluated. The synthesized compounds consisted of two novel series of imidazole derivatives containing dithiocarbamate (5a-5g) and (benz) azolethiol (6a-6n) side chains that are structurally related to the famous antifungal azole pharmacophore. Their structures were characterized by spectral (IR, ${ }^{1} \mathrm{H}$ NMR, ${ }^{13} \mathrm{C}$ NMR, and MS spectra) analyses. The synthesized compounds were screened for in vitro antifungal activity against pathogenic strains of fungi. Theoretical ADME predictions were calculated for final compounds. A molecular docking study of the most active compound with target 'lanosterol 14 $\alpha$-demethylase' (CYP51) [4] was performed to unravel the mode of antifungal action.

Compound 5e, which features imidazole and 4-methoxybenzyl piperazine scaffolds, showed the most promising antifungal activity with a MIC 50 value of $0.78 \mathrm{ug} / \mathrm{mL}$ against Candida krusei. The effect of the compound 5e against ergosterol biosynthesis was observed by the LC-MS-MS method, which is based on quantification of the ergosterol level in C. krusei. Significant interactions were also observed between compound $5 \mathbf{e}$ and $14-\alpha$-sterol demethylase. In addition to good antifungal activity, all compounds in the series exhibited a good predicted pharmacokinetics profile.

Acknowledgments: This study was financially supported by Anadolu University Scientific Projects Fund, Project No.: $1705 S 312$.

Author Contributions: Y.Ö. conceived and designed the experiments; A.I. and U.A.C. performed the synthesis; S.L. performed analysis studies; B.N.S. performed activity tests; B.N.S. performed docking studies; B.N.S., A.I., U.A.C., Y.Ö. and S.L. wrote the paper.

Conflicts of Interest: The authors declare no conflict of interest.

\section{References}

1. White, T.C.; Marr, K.A.; Bowden, R.A. Clinical, cellular, and molecular factors that contribute to antifungal drug resistance. Clin. Microbiol. Rev. 1998, 11, 382-402.

2. Shah, J.J.; Khedkar, V.; Coutinho, E.C.; Mohanraj, K. Design, synthesis and evaluation of benzotriazole derivatives as novel antifungal agents. Bioorg. Med. Chem. Lett. 2015, 25, 3730-3737. 
3. Wani, M.Y.; Ahmad, A.; Shiekh, R.A.; Al-Ghamdi, K.J.; Sobral, A.J. Imidazole clubbed 1,3,4-oxadiazole derivatives as potential antifungal agents. Bioorg. Med. Chem. 2015, 23, 4172-4180.

4. Larissa, M.P.; Thomas, L.P.; Michael, R. Crystal structure of cytochrome P450 $14 \alpha$-sterol demethylase (CYP51) from Mycobacterium tuberculosis in complex with azole inhibitors. PNAS 2001, 98, 3068-3073.

(C) 2017 by the authors. Licensee MDPI, Basel, Switzerland. This article is an open access article distributed under the terms and conditions of the Creative Commons Attribution (CC BY) license (http://creativecommons.org/licenses/by/4.0/). 